\title{
Goya en el hipertexto: multirrelato y motivaciones artísticas
}

\section{Goya in the hypertext: multinarration and artistic motivations}

\author{
Francisco García García ${ }^{1}$ \\ Universidad Complutense de Madrid. Madrid, España \\ fgarciag@ucm.es \\ Francisco José Gil Ruiz ${ }^{2}$ \\ Universidad Complutense de Madrid. Madrid, España \\ franciscojosegilruiz@ucm.es
}

\section{RESUMEN}

En una actualidad marcada por la convergencia de medios y formatos, de datos abiertos y de navegación a través de enlaces e infinidad de contenidos, es pertinente profundizar en cómo el ámbito cultural más tradicional -en este caso la pintura- se adapta a las cotidianidades tecnológicas. Goya no ha perdido vigencia, y como el resto de la cultura, vive ya no solo en la pintura, libros y demás formatos analógicos; es un habitante del mundo virtual que cada vez nos es más real.

En primer lugar, este trabajo aborda varios principios de la narrativa hipertextual aplicados a la figura de Francisco de Goya y Lucientes mediante la construcción de un relato capaz de desglosarse en bloques conectados a textos externos (web) e internos, proporcionando miles de posibilidades narrativas para acceder al mundo y la obra de Goya, y generando un multirrelato. En segundo lugar, partiendo del multirrelato, se realiza una clasificación de una muestra de 14 obras de Goya con las siguientes categorías: Pintura por actividad profesional, Pintura como testimonio histórico, Pintura por placer, y Pintura por necesidad. Los resultados muestran la combinación del comentario artístico tradicional con la construcción del relato hipertextual, ofreciendo una línea de investigación pertinente y consecuente con el mundo digital.

PALABRAS CLAVE: Goya, hipertexto, relatos digitales, arte.

\begin{abstract}
In a present so much marked by the media and formats convergence, by open data, and by a navigation through links and an infinity of contents, it is pertinent to deepen in how the most traditional cultural field -in this case, painting- is adapted to the current technologies. Goya has not lost validity, and like the rest of culture, he lives not just by the painting, the books and other analogic formats; he is a habitant from the virtual world which is increasingly more real.

In the first place, this paper approaches some principles of the hypertextual narrative applied to Francisco de Goya y Lucientes though the construction of a narration which is able to be broken in blocks linked to external (web) and internal texts, providing thousands of narrative possibilities to access to the Goya's world and paintings, and developing a multinarration. In the second place, starting from the multinarration, we make the classification of a sample made by 14 paintings from Goya, in this categories: Painting for professional activity, Painting as historical testimony, Painting for pleasure, and Painture by need. The results show the combination of the traditional artistic commentary with the hypertextual narration construction, offering a research line pertinent and consecuent with the digital world.
\end{abstract}

KEYWORDS: Goya, hypertext, digital narrations, art. 


\section{Introducción}

El ciudadano está conectado a un flujo de información permanente, siendo susceptible de acoger todo tipo de ideales de vida, de conocer el pasado y el presente, y de imaginar el futuro. Murray (1999) se atrevió a imaginar algunas de las consecuencias de los cambios sociales que el ámbito digital nos proporciona, con especial atención a las narrativas, que siguen y seguirán vigentes mientras la tecnología continúa su espiral de desarrollo. La transparencia es un valor a tener en cuenta a pesar de los aspectos negativos señalados por Han (2013), pues solo las máquinas pueden ser transparentes, mientras que el ser humano necesita de esferas propias y no compartidas (p. 14). Es más, en otro trabajo (2014) el autor niega que lo digital sea de las masas, sino de enjambres compuestos por individuos aislados (p. 26) El Big Data está en todas partes, nos rodea y nos modifica, "presenciamos cómo el tsunami digital arrasa con hábitos y costumbres, además de proponer nuevas profesiones, términos o maneras de comunicarnos que hace tan solo unos años no hubiéramos imaginado." (Fernández, 2017, p. 17). Este trabajo tiene dos propósitos principales: recorrer los conceptos relacionados con el hipertexto con el fin de crear un multirrelato sobre la vida y obra de Goya, y exponer una serie de motivaciones susceptibles de clasificar la obra del pintor.

En suma, se aunarán la investigación biográfica y artística mediante los principios hipertextuales de las narraciones digitales, logrando así un conocimiento más profundo y plural a través de los enlaces que componen hipertextos. Construir un relato le da un sentido global, diverso (dadas las combinaciones posibles), significativo en cuanto al valor de la narratividad y la diversidad de elección de la perspectiva narrativa. Por tanto, el contexto de esta investigación es pluridisciplinar, en un punto de encuentro entre la tecnología y sus usos, la comunicación, el arte y la educación. Los públicos o destinatarios de esta investigación son de diversa naturaleza: los expertos en arte, especialmente los interesados en la obra de Goya; los estudiosos del uso del hipertexto en diferentes ámbitos, como el artístico, el comunicativo y el educativo; los docentes y discentes, que pueden encontrar en esta propuesta estrategias para el conocimiento de este autor desde distintas perspectivas; investigadores/as que utilicen estas estrategias aplicadas a otros artistas, autores, materias y formatos de comunicación, discurso o expresión.

Consideramos que Internet no deja de ser un medio de democratización social, tal vez no para las masas, pero sí para los individuos. Castells (2010) acierta diciendo que las acciones más cotidianas de nuestra vida se realizan ya en entornos digitales y globales, incluyendo aquí la cultura y los espectáculos. El Open Data fomenta esa democratización y generación de poder cultural del ciudadano, base de su naturaleza:

The philosophy behind this movement is, at its foundations, truly centered on the citizen. In this sense, free access to data contributes to an enhancement of democratic institutions from a citizen's point of view. This event must help to enrich democratic debate, stimulate public life, and contribute to renewing public services. Open Data is a political process whose message is built around 
transparency in innovation and in the development of public action. (Monino; Sedkaoui, 2016)

\section{Marco teórico}

\subsection{El relato no lineal}

La no linealidad es el principal "modus operandi" del ámbito digital; los contenidos se copian, fragmentan, transforman, difunden... todo ello en flujos de datos. Como dice Manovich (2005), los objetos de los nuevos medios obedecen a valores matemáticos y algorítmicos, mientras que los objetos analógicos son "continuos", al no albergar unidades indivisibles ${ }^{\mathrm{i}}$. La digitalización muestrea y cuantifica (pp. 72-73), por lo que el relato está sujeto a valores numéricos concretos, entendidos por Quéau (1995) como intermediarios para generar y enlazar contenidos, siendo forma y a su vez, enlaces a otras formas (pp. 157-158) Esos contenidos digitales son textuales, por lo que en términos de García García (2006) son también escritura y lectura, con la mediación de una interfaz (p. 6).

La linealidad se pierde en el momento en que el usuario navega entre webs, gestando su relato mediante su acción -los "clics"- y confirmando las dimensiones narrativas del texto, es decir, como en todo texto narrativo, lo fundamental es la acción, tal y como subrayan Contursi y Ferro (2000 p. 30). Los postulados narrativos tradicionales tienen su causa primordial en la Poética de Aristóteles en cuanto al orden causal de acontecimientos, fundamentados en un orden temporal. ${ }^{\text {ii }}$ El texto digital ha modificado la acción concreta del usuario sobre la información que maneja de primera mano, pero coincidimos con Contursi y Ferro (2000) en que lo importante son los usos de los sujetos sobre las narraciones. (p. 100), pues al navegar, seleccionamos, desechamos, ignoramos contenidos (textos)... sin una ruta marcada o prefijada. Somos exploradores en una jungla de datos, apartando maleza, evitando trampas, avanzando y retrocediendo en función de los peligros. Así son las narrativas no lineales:

Un texto no lineal es un objeto de comunicación verbal que no consiste simplemente en una secuencia fija de letras, palabras y frases; es un texto cuyas palabras o secuencias de palabras pueden variar de lectura debido a la forma, las convenciones o los mecanismos del texto. Los textos no lineales pueden ser muy diferentes entre sí, por lo menos tan diferentes como lo son de los textos lineales. (Aarseth, 1997, p. 71)

La narración no lineal se compone de textos que contienen relatos y/o partes de relatos que, como dice García García (2006), pueden tener varias posiciones para conformar el discurso final (p. 14). Se accede a todo y a nada a la vez, el compromiso del usuario (lector) con el texto es volátil en función del compromiso de las circunstancias, pues como indica Ortega Santamaría (2004), intervienen numerosas variables de diversa índole, que son las que determinan la presencia o ausencia de linealidad. ( p. 63)

Los textos se combinan entre sí por nuestra acción sobre el material, en términos de Cordón (2016), dando lugar a una legibilidad ecléctica (p. 26) que choca con el discurso

Goya en el hipertexto: multirrelato y motivaciones artísticas. Francisco García García y 
narrativo tradicional donde Chatman (2013) distingue el discurso, (el "cómo"), del contenido, (el "qué"). Orden, duración y frecuencia se disgregan junto con el contenido en la no linealidad, pudiendo acaparar no sólo un texto concreto, sino conjuntos de los mismos, dando pie a combinar, como dijo Liestol (1997), números, palabras, dibujos, gráficos, fotografías, sonido y video. (p. 140).

El texto se proyecta hacia el hipertexto, -cuya lectura es no lineal y discontinuaiii - que puede apoyarse en el hipermedia, y que posee la capacidad de traspasar las fronteras narrativas y mediáticas (transmedia).

\subsection{Hipertexto e Hipermedia}

Los expertos sitúan a Nelson $(1965)^{\mathrm{iv}}$ como el principal precursor hipertextual, que el ciudadano utiliza relacionando informaciones, emulando "la organización asociativa de la memoria humana" (Campás, 2007, p.41)

Landow (1997) presenta el hipertexto como "una tecnología informática que consiste en bloques de texto individuales, las lexías, con enlaces electrónicos que los enlazan entre ellos (...) (1997, p. 17); Codina (1998) define hipertexto como "una estructura de la información que organiza un conjunto de elementos en forma de red."v; para Murray (1999) "es un conjunto de documentos de cualquier clase (imágenes, texto, tablas, vídeos) conectados entre sí por medio de enlaces.“ (p. 66); y recientemente fue definido como "una estructura construida a partir de los enlaces que unen textos o contenidos multimedia mediante la interacción del usuario en un entorno digital y multilineal." (Arias-Robles; García-Avilés, 2016, p. 64) vi $^{\mathrm{vi}}$

Los textos se enlazan, copian, transforman, distribuyen y consumen masivamente, hasta tal punto que los contenidos de un texto pueden formar parte de otros muchos. Es por eso viable citar los postulados a este respecto de Genette (1979), que distingue cinco tipos de transtextualidad: el intertexto implica la presencia simultánea entre dos o más textos; el paratexto se refiere a los añadidos que complementan un texto (notas, anexos, comentarios, prólogo...); el metatexto es la alusión de un texto a otro sin ser citado; el architexto es el conjunto de categorías que implica la clasificación del texto (por ejemplo, el género); y llama hipertexto a "todo texto derivado de un texto anterior por transformación simple (...) o por transformación indirecta, diremos imitación." (Genette, 1979, p. 15) Como indica el mismo autor, en estos tipos de transtextualidad, de eco, de presencia de unos textos en otros, no es raro encontrar simultaneidad de categorías, más aun teniendo en cuenta que actualmente medios, contenidos, informaciones... convergen y se extienden, y en esa extensión se sitúan las narrativas transmedia, concepto introducido por Jenkins (2003) ${ }^{\text {vii }}$, y definido por Scolari (2013) como una expansión del relato a lo largo de otros medios y plataformas de comunicación (p.27). Prósperi (2016) habla del palimpsesto textual desde el punto de vista literario, aduciendo que los textos se escriben borrando lo escrito previamente.

Del hipertexto parte el Hipermedia. Torres (2009) define hipermedia "como multimedia interactiva, una forma de expresión donde convergen medios audiovisuales de diversos tipos articulados en una interfaz que permiten la interacción con el usuario." (p. 152). Moreno (2012) especifica: "Hipermedia designa la convergencia interactiva de medios y sustancias expresivas de los mismos (...) en soportes digitales (...) en los que el 
receptor-lector se convierte en lectoautor, en coautor del programa seleccionado, transformando e incluso construyendo. " (p. 21)

Así, todo es un conglomerado de textos, acuciado por el efecto de las redes sociales, que multiplican los enlaces entre contenidos, y el ámbito cultural y artístico es susceptible de ser también "enlazado" dentro de ese enjambre que Han (2014) describe como ruidoso, narcisista y veloz, tanto, que Giraldo-Dávila y Maya Franco (2016) estipulan necesaria una "Economía de la Comunicación". viii

\subsection{Interactividad y cooperación}

El Open Data da acceso a datos susceptibles de conformar relatos, ofreciendo un "flujo de contenido a través de múltiples plataformas mediáticas, la cooperación entre múltiples industrias mediáticas y el comportamiento migratorio de las audiencias mediáticas, dispuestas a ir casi a cualquier parte en busca del tipo deseado de experiencias de entretenimiento." (Jenkins, 2008, p. 14). Dichos flujos adquieren prácticamente cualquier forma gracias a la naturaleza de la red, identificada por Castells (2009) en tres términos: flexibilidad, adaptabilidad, y capacidad de supervivencia ( $\mathrm{p}$. 49).

Estas cualidades fomentan la interactividad, que De Pablos Pons (2004) contempla desde la implicación del usuario en el texto a la hora de elegir estrategias de lectura, y que García García (2006) sintetiza como diálogo entre el ordenador y el usuario (p. 13), entre la persona y la máquina. La implicación y el diálogo son en este trabajo las claves de una interactividad que alimenta el feedback permanente, donde todo se duplica, se imita, se parodia, se transforma, se intercala, se inspira... y se entrelaza. Indica García García (2002) que todo contacto con objetos culturales exige interactividad, pero en el marco narrativo digital, la interactividad se dispara gracias a los "clics", de manera que surge también la cooperación, en ese vínculo interactivo entre usuarios y textos sin un orden definido. En palabras de García García (2002), este es un contexto heterárquico ix, donde cada cual aporta según su propósito: "la heterarquía es el poder compartido, las alternativas a un orden único, la atención a proyecto frente a lo dado previamente y por eso favorece la creatividad, la razón crítica, la pluralidad de voces, de enfoques y de puntos de vista." (p. 3)

Observamos que estos conceptos descritos brevemente convergen en lo que consideramos las narrativas digitales. La no linealidad alimenta al hipertexto, que alberga el hipermedia, se reproduce con la interacción, y se promueve con la cooperación. Estos elementos pueden considerarse para el aprendizaje y la investigación al fomentar la generación de relatos, pues como dice Gros (2012), el entorno digital permite "(...) compartir la investigación, compartir los recursos y compartir los resultados" (p. 10), a lo que podemos sumar, atendiendo a Vera Silva (2017) el intercambio y la cooperación para solucionar problemas planetarios (p. 101), así como la idea de la consiliencia ${ }^{\mathrm{x}}$ de cara a la educación, donde los estudiantes digitales investigan un tema a través de unidades de conocimiento (pp. 122-123).

\subsection{Goya, justificación narrativa}

El arte y la cultura forman parte del oleaje de ese "Mare Nostrum digital" (García García; Gértrudix, 2009) que todo lo acapara y lo muestra, a pesar de que, según 
Gértrudix-Barrio et al. (2016), los jóvenes den escasa la relevancia a la alfabetización digital y que, como dijo Murray (1999), a pesar de todo, seamos incapaces de comunicarnos. (p. 290). El arte está en las redes sociales, tiene su impacto en las comunidades, es accesible, y tiene conectividad con el ciudadano: introduciendo cualquier concepto en un buscador accederemos páginas web con información susceptible de ser consultada, aprovechada, desechada, o ignorada. El sujeto aprende en función de lo que las fuentes puedan ofrecerle en un modelo narrativo susceptible de múltiples posibilidades. Para Murray (1999) esa multifuncionalidad está directamente vinculada a cómo pensamos y actuamos, y la mejor forma de plasmar esos hechos es mediante el ordenador (p. 49).

Si a lo largo del siglo XX el museo pasó de ser un espacio eminentemente educativo a un lugar capaz de entretener al visitante (Mihura López et al., 2012, p. 1301), ahora es otro entorno digital dentro de la inmensa red que nos rodea. El lienzo se digitaliza, dando paso al "museo social". (Claes y Deltell, 2014 p. 595). El museo es un espacio cultural de tradición readaptado a las necesidades de un presente dúctil, binario, abierto, que incluye "la reorganización de los principios culturales preexistentes. Lo digital revoluciona las relaciones entre la materialidad del objeto y la identidad del texto, así como entre materialidad y formas de circulación” (...) (Cordón, 2016, p. 32).

Decía Walter Benjamin (2015) que la pintura no era un arte para disfrutar en masa como pudiera serlo el cine, pero eso ha cambiado al ramificarse por la World Wide Web; la experiencia de disfrute y aprendizaje del arte es posible ahora desde cualquier hogar y aula, y como puntualizan Mihura et al. (2012), los ciudadanos pueden acceder a las obras de arte de una manera no limitada por las salas físicas de los museos, con una accesibilidad atrayente para cualquier edad (p. 1304), con las aplicaciones educativas que López Valero y Jerez Martínez (2015) achacan al entorno digital. Así, los museos reciben reconocimiento por compartir de manera altruista la información de sus fondos. (Martín Bravo, 2015, p. 162).

Francisco de Goya y Lucientes ha suscitado multitud de estudios que lo han encumbrado a lo más alto de la cultura española. Dibujó lo peor de la sociedad española de su época, algo que, como dice Antigüedad del Castillo-Olivares (2009-2010), le traería problemas con la Iglesia sin impedirle ser un pintor sobresaliente pero trágico dada su sordera. Su labor fue más allá de la pintura dada la gran variedad de herramientas y formatos que utilizó. Tanto es así, que ha tenido su extensión en el cine como "el medio por el que los creadores cinematográficos se habían servido para mostrarnos un período histórico (...)" (Águeda Villar, 2001, p. 100). Aplicar el hipertexto a esta figura es una tarea fructífera y de interés que subraya el poder didáctico y humanístico de los principios digitales, enlaces de acceso cotidianos a la cultura, al empoderamiento ciudadano.

Ortega y Gasset (1980) se aproximó a Goya e intentó acceder a su "yo" más íntimo y coherente, que explicase de alguna manera la genialidad de este hombre de su tiempo, no sólo por lo que pintó, sino también por lo que no pintó. (p. 286); un hombre cuya vocación era su profesión (pp. 334-335). Prada (2008) identifica a Goya como un hombre ambicioso y muy seguro de sí mismo, incluso al comienzo de su carrera, de lo que se desprende un compromiso total con su profesión, que quitó protagonismo a otras facetas de su vida.

Goya en el hipertexto: multirrelato y motivaciones artísticas. Francisco García García y Francisco José Gil Ruiz. 
Ortega (2016) sitúa el arte como el conjunto de medios que tratan las figuras y pasiones humanas (p.57), de modo que no es extraño que se repitan esas figuras y pasiones embutidas en la subjetividad del artista. El reto es captar lo que ese artista quería plasmar, y a la vez, lo que plasmó inconscientemente; ahí radica el arte como testimonio histórico, social, y personal, de ahí se extraen las narraciones sobre el artista y su obra. Es lo que le otorga sustancia y favorece a un goce estético inteligente, pues todo "placer estético tiene que ser un placer inteligente. Porque entre los placeres los hay ciegos y los hay perspicaces." (Ortega y Gasset, 2016, p. 74)

En la obra de Goya observamos múltiples dimensiones textuales dadas sus mezclas temáticas de creencias populares, mitológicas, sociales... ${ }^{\text {xi }}$, así como varias formas de explotación al dividir su creación en arte público (encargos) y arte privado (emociones y percepciones personales) $)^{\mathrm{xii}}$.

Mediante la actividad hipertextual, la historia y el arte se pueden desglosar, evidenciar, hacer notorio y promover. Nos encontramos ante la posibilidad de crear grandes relatos abiertos partiendo de todo tipo de textos que convergen en una temática o ítem concreto, en este caso, Goya, quien vivió momentos cruciales de la historia de España, retratando a grandes personajes, sucesos, costumbres, tradiciones, y arquetipos mitológicos, religiosos y psicológicos. Dio color a sus propias concepciones del mundo, atreviéndose a plasmar, citando a Freeland (2003), los horrores internos del ser humano, su naturaleza terrible (pp. 40-41), adelantándose a su tiempo y desarrollando el lenguaje expresionista (Prada, 2010, p.148). Acercarse a Goya es acercarse a $s u$ historia y a $l a$ historia. Este trabajo plantea un experimento de multirrelato hipertextual para acercarse a él y a sus motivaciones personales, ${ }^{\text {xiii }}$ todo ello teniendo en cuenta la apertura que la red ofrece al conocimiento, una apertura en la que, como indica Vera Silva (2017), un ciudadano puede desarrollar diversas competencias, entre ellas las referidas a materias artísticas, y donde el límite estará en la propia capacidad humana para entender este contexto (p.94).

\section{Objetivos e hipótesis}

\subsection{Objetivos}

- Diseñar la construcción de un multirrelato que haga converger principios de las narrativas digitales con un comentario artístico tradicional.

- Subrayar las capacidades culturales y educativas del multirrelato hipertextual.

- Analizar la narración desde la perspectiva del hipertexto, en un recorrido sobre la vida de Francisco de Goya y Lucientes.

- Analizar y describir la obra de Goya desde el punto de vista de su motivación.

\subsection{Hipótesis}

- La construcción hipertextual genera, junto con las estrategias digitales de la no linealidad y de la interacción, diversidad de lecturas de la vida y obra de Francisco de Goya, unidas en un multirrelato.

- El multirrelato digital de la obra de Goya ofrece relatos susceptibles de empoderar al ciudadano en su conocimiento y enriquecimiento cultural.

- La obra de Goya es observable según la perspectiva de distintas miradas: Pintura por actividad profesional, Pintura como testimonio histórico, Pintura por placer, y Pintura por necesidad. 


\section{Metodología}

Tras la fundamentación teórica referente a los elementos hipertextuales, se propone un análisis de los mismos aplicados a la obra Goya, tanto en sus aspectos biográficos como artísticos, de tal manera que se pueda leer el resultado de la narrativa construida desde diversas perspectivas que cada lector actualiza y experimenta según su propia elección. Es así, por tanto, una construcción de texto que activa el lector en general o el discente en particular a través de las elecciones múltiples que le concede el sistema hipertextual empleado. En este sentido, cuando se lleva a cabo este tipo de lectura, cada lector experimenta la creación de su propio relato. ${ }^{\text {xiv }}$

Se propone construir, por tanto, un relato divisible, reordenable, interactivo, hipertextual y cooperativo de la vida y obra de Goya; cada bloque del relato total (referente a una etapa de la vida de Goya) se dividirá en fragmentos numerados (lexias según Barthes (2004, p. 9); lexía o bloque según Landow ${ }^{\mathrm{xv}}$ ), dando lugar a una serie de enunciados que a su vez, se desglosarán en los apartados: Relaciones, Espacios, Temáticas, y Pintura por: actividad profesional, por placer, pintura como testimonio histórico, y pintura por necesidad. Este punto se refiere a los tipos de motivación propuestos, y será abordado mediante la interpretación a partir de los datos de los enunciados de cada bloque y de las lexías que incluye.

Con esta fórmula de trabajo se construirá un hipertexto que pueda abarcarse de manera no lineal, que incluya enlaces a contenidos web, y que exija la interacción y cooperación del lector/usuario. Dada la magnitud de la obra de Goya (en calidad y cantidad), realizamos una selección de entre dos y cuatro obras en cada etapa del artista ${ }^{\mathrm{xvi}}$, pues resulta inviable acaparar la totalidad. La muestra es representativa de lo que cada fragmento cuenta sobre Goya, y bastará para un análisis interpretativo de su motivación.

\subsection{Propuesta hipertextual de Goya ${ }^{\text {xii }}$}

\section{1- Goya: nacimiento, formación y primeras aportaciones}

1.1) Francisco de Goya y Lucientes (1746-1828) nació en Fuendetodos, Zaragoza, siendo el cuarto de seis hermanos. 1.2) Tras la escuela, trabaja como aprendiz en el taller de José Luzán, que era "como una escuela de arte provista de una buena colección de diapositivas" (Hughes, 2004, p.49) para pasar luego a continuar formándose con Francisco Bayeu Subías, a través del cual conocería a Josefa Bayeu, su esposa en 1773.

1.3) Se traslada a Madrid en 1763 tras sacar adelante varios trabajos en Zaragoza, así como el Relicario de la Parroquia de Fuendetodos (atribuido a echa de 1765) con el fin de hacer carrera en la corte. 1.4) En vista de las dos negativas recibidas para entrar en la Academia de San Fernando (en 1763 y en 1766) y de que "Carlos III amaba Italia y solía juzgar todos los acontecimientos culturales según los parámetros italianos y franceses, antes que españoles" (Hughes, 2004, p. 49), Goya viaja a Italia en junio de 1769, donde asimilaría un nuevo aprendizaje del arte que se vería reflejado en "Aníbal vencedor contempla por primera vez Italia desde los Alpes."xviii

1.5) Relaciones: las más influyentes en Goya fueron:

1.5.1) Francisco de Goya y Lucientes tuvo cinco hermanos.

1.5.2) Fue aprendiz de José Luzán y de Francisco Bayeu Subías.

Goya en el hipertexto: multirrelato y motivaciones artísticas. Francisco García García y 
1.5.3) Conoció a Josefa Bayeu.

1.6) Espacios: Goya se desenvolvió en:

1.6.1) Fuendetodos: lugar de nacimiento de Francisco de Goya y Lucientes.

1.6.2) Zaragoza: lugar de inicios profesionales de Francisco de Goya y Lucientes.

1.6.3) Madrid: lugar de tempranos fracasos de Francisco de Goya y Lucientes.

1.6.4) Roma: lugar de perfeccionamiento de Francisco de Goya y Lucientes.

1.7) Temáticas: Goya abordó: 1.7.1) Historia; 1.7.2) Religión.

\section{8) Obras seleccionadas}

1.8.1) Relicario de la Parroquia de Fuendetodos. 1765.

1.8.2) "Aníbal vencedor, que por primera vez miró Italia desde los Alpes" 1771.

\section{9) Pintura por:}

Atendiendo a las obras seleccionadas y circunstancias señalados del artista, en esta época predomina la Pintura por actividad profesional: son años en los que Goya necesita demostrar su saber hacer, sacar partido del aprendizaje con Luzán y Bayeu y del viaje a Roma. El relicario sería uno de sus primeros encargos profesionales, y el "Anibal vencedor..." su consolidación europea a nivel formativo. Entendemos que en ambos se ajusta a características concretas de encargo y concurso respectivamente, haciendo todo lo posible por destacar dentro de las condiciones establecidas, y especialmente con el "Aníbal...", tuvo un punto de inflexión en cuanto a influencias y principios. Mediante la sumisión a las condiciones de estas obras, podemos vislumbrar el firme compromiso del artista para con su vocación.

\section{2- Goya: inicios profesionales}

2.1) Tras volver de Italia, Goya realiza su primer encargo: el fresco del coreto de la Basílica del Pilar de Zaragoza, titulado "Adoración del nombre de Dios" (1771-1772). 2.2) Le siguen otros en Zaragoza, como el conjunto de pinturas para la cartuja del Aula Dei: once grandes pinturas murales sobre la vida de la Virgen, terminados a finales de 1774 y que Hughes (2004) destaca como todo un hito dada la juventud del artista respecto a la magnitud del encargo (p. 56). 2.3) Vuelve a Madrid en enero de 1775 para trabajar como pintor de cartones de tapices en la Real Fábrica de Tapices de Santa Bárbara, pintando, como apunta Hughes (2004), más de sesenta cartones que solo se verían en la Corte (p.103), donde destacan los majos: "Goya retrata una idealizada clase baja, procedente tanto del campo como de la ciudad, y en especial a los majos y a sus compañeras."(p. 104). 2.4) En "La Pradera de San Isidro" (1788) reúne a los madrileños de la época en el festejo del santo labrador, ilustrando una realidad costumbrista de la sociedad de su tiempo. No obstante, hay en este punto otras opiniones, pues para Prada (2008) no era la intención del pintor ser cronista social con estas obras (p.74).

2.5) Relaciones: las más influyentes en Goya fueron:

2.5.1) Se casa con Josefa Bayeu en 1773 .

2.5.2) Mantiene relación con Francisco Bayeu Subías.

2.6) Espacios: Goya se desenvolvió en:

2.6.1) Zaragoza: primer encargo a gran escala.

2.6.2) Madrid: en la Real Fábrica de tapices de Santa Bárbara, Goya tuvo empleo fijo largo tiempo.

2.7) Temáticas: Goya abordó: 2.7.1) Religión; 2.7.2) Folclore español; 2.7.3) Sociedad.

Goya en el hipertexto: multirrelato y motivaciones artísticas. Francisco García García y 


\section{8) Obras seleccionadas}

2.8.1) "Adoración del nombre de Dios por los ángeles" (1771-1772)

2.8.2) "La pradera de San Isidro" (1788)

\section{9) Pintura por:}

Según los datos y obras presentes en este tramo biográfico, contemplamos pintura por actividad profesional en ambas obras. La "Adoración..." es un encargo que le permite seguir acumulando méritos a la espera de futuros trabajos, y como en toda relación causa-efecto, su hacer le llevaría a lograr un puesto fijo en Real Fábrica de Tapices. Esa docilidad respecto a su capacidad de adaptación a los encargos tuvo una recompensa: poder ampliar las temáticas de sus cuadros. En la Real Fábrica de Tapices ya no tuvo que centrarse en aspectos religiosos; se observa una plasmación histórica de las gentes y costumbres de la época, que entronca con la Pintura como testimonio histórico: Goya esboza imágenes cotidianas de su tiempo que bien sirven como apunte histórico de la sociedad, especialmente, atendiendo a las clases bajas: majas, majos, peleles, ancianas... Todos ellos se consolidaron como arquetipos del pintor. "La pradera de San Isidro" es un claro ejemplo de pintura como testimonio histórico, ofreciendo las observaciones de Goya hacia la sociedad que le rodeaba, observaciones subjetivamente positivas, vivas y alegres, que contrastan con las pinturas negras de tiempos posteriores.

\section{3- Goya: de la Real Fábrica de Tapices a la Corte}

3.1) Paralelamente a su actividad en la Real Fábrica de Tapices, Goya ingresa, en julio de 1780, en la Real Academia de las Artes de San Fernando como miembro de mérito por su "Cristo crucificado", sobre lo cual apunta Prada (2008, p. 91) que el pintor se cree ya libre de tutelas sociales. 3.2) En 1871 le fue revocado un encargo en la basílica del Pilar de Zaragoza, costándole desavenencias con Bayeu (Goya se negaba a que éste supervisara su trabajo). 3.3) En 1873 termina el encargo del Conde de Floridablanca en la Basílica de San Francisco el Grande: la "Predicación de San Bernardino de Siena". A partir de ahí Goya tiene gran actividad como retratista, prosperando en relaciones, como las que tuvo con la familia del duque de Osuna ${ }^{\text {xix }}$, retratados en "Los duques de Osuna y sus hijos" (1787-1788). 3.4) Logró en 1785 el nombramiento de teniente director de la Academia de San Fernando, y en 1786, de Pintor del rey.

3.5) Relaciones: las más influyentes en Goya fueron:

3.5.1) Discusión con Francisco Bayeu Subías.

3.5.2) El Conde de Floridablanca le proporciona trabajo.

3.5.3) La Familia de Osuna le brinda buena reputación como retratista.

3.5.4) Queda al servicio de la Corte de Carlos III.

3.6) Espacios: Goya se desenvolvió en:

3.6.1) Madrid: entra en la Real Academia de Bellas Artes de San Fernando, y trabaja en la Real Fábrica de Tapices.

3.7) Temática: Goya abordó: 3.7.1) Religión; 3.7.2) Retratos; 3.7.3) Sociedad;

3.7.4) Clases altas, 3.7.5) Clases bajas; 3.7.6) Folclore español.

\section{8) Obras seleccionadas}

3.8.1) "Cristo crucificado" (1780)

3.8.2) "Los duques de Osuna y sus hijos" (1787-1788)

\section{9) Pintura por:}

Los datos de este bloque permiten afirmar que Goya mantuvo la Pintura por actividad profesional en la medida en que los retratos le permitieron contactar con la alta clase social de la época. No obstante, su buena relación y afinidad con la familia de Osuna

Goya en el hipertexto: multirrelato y motivaciones artísticas. Francisco García García y 
invita a interpretar un sentimiento de placer al retratar a estas personas. Es pertinente, por tanto, contemplar que exista Pintura por placer al menos concretamente en este caso. Respecto del "Cristo crucificado", a la actividad profesional se le suma, en la misma medida, la pintura por necesidad, ya que el acceso a la Real Academia de San Fernando, algo que hasta entonces le había sido imposible, por fin se hizo realidad. Ser "miembro de mérito" de esta institución le supondría, entendemos, una satisfacción no solo profesional, sino también personal dado el reconocimiento alcanzado. Goya estaba a la altura de los mejores de su tiempo.

\section{4- Goya: enfermedad, Guerra de la Independencia y Pintor de Cámara}

4.1) A la muerte de Carlos III, Goya trabajó para Carlos IV y su familia, que como apunta Hughes (2004), apreciaban verdaderamente el talento del artista (p. 169). 4.2) El aprecio de Goya hacia la familia real es palpable en "Familia de Carlos IV" (1800), donde, siguiendo con Hughes, Goya realiza una "apología entusiasta de la monarquía" (p. 261). 4.3) A finales de 1790 sufrió las primeras afecciones de una enfermedad que se agudizó estando él en Sevilla en 1793, y que le dejaría sordo contando 46 años. Guijarro Castro (2013) subraya en su estudio el cambio de estilo de Goya a raíz de su enfermedad, además de los cambios que esta discapacidad supuso en su vida, como tener que abandonar la enseñanza (p. 17). Propuso como diagnósticos, por un lado, el síndrome de Susac, y por otro, malaria cerebral. El tratamiento prolongado de quinina (corteza de cinchona) le habría provocado la sordera. (p. 19)

4.4) Goya anuncia en 1799 su colección de "Caprichos", un desahogo propio sobre los vicios y errores de la sociedad ${ }^{\mathrm{xxi}}$. Logra en ese año también el título de Pintor de Cámara en 1799, dando lugar a una etapa artística y profesionalmente muy fructífera hasta la Guerra de Independencia (1808-1814). Juró fidelidad a José Bonaparte, para pasar luego a disposición de Fernando VII, que le terminaría de financiar las obras del 2 y el 3 de mayo de 1808. ${ }^{\text {xii }}$ La Guerra de Independencia sería un tema pictórico que marcaría un hito en Goya, dando lugar, además, a su serie "Desastres de la guerra":

En cierto modo, algunos de los Desastres de la Guerra se corresponden con una preparación artística de las obras ulteriores de El dos de mayo de 1808 y El tres de mayo de 1808. Sobre todo existen similitudes tanto en la estructura como en el contenido entre los dos lienzos y algunos de los Desastres de la Guerra (...) (Jacobs, 2016-2017, p. 63)

4.5) Relaciones: las más influyentes en Goya fueron:

4.5.1) A la muerte de Carlos III, Goya siguió trabajando para los reyes Carlos IV y María Luisa de Parma, admiradores de la obra de Goya.

4.5.2) Goya tuvo que abandonar la enseñanza por la enfermedad que le dejaría sordo.

4.6) Espacios: Goya se desenvolvió en:

4.6.1) Tuvo su principal actividad en Madrid en estos años.

4.6.2) En Sevilla enfermó de la dolencia que le dejaría sordo.

4.7) Temáticas: Goya abordó: 4.7.1) Retrato; 4.7.2) Realeza; 4.7.3) Guerra.

4.8) Obras seleccionadas

4.8.1) "Caprichos". xxiii 1799.

4.8.2) "Familia de Carlos IV'. 1800.

4.8.3) El 2 de Mayo de 1808 en Madrid o "La lucha de los mamelucos". 1814.

4.8.4) El 3 de Mayo en Madrid o "Los fusilamientos". 1814.

Goya en el hipertexto: multirrelato y motivaciones artísticas. Francisco García García y

Francisco José Gil Ruiz.

Página 11 de 27 


\section{9) Pintura por}

Incluimos los "Caprichos" en Pintura por placer. En ellos explora multitud de temas, escenas, arquetipos... de manera libre y mordaz, y el simple concepto de capricho ya invita a conectar esta actividad con el placer. Los "Caprichos", tienen en común con las demás obras seleccionadas la Pintura como testimonio histórico, pues las estampas y los retratos, aquí concretamente el de la "Familia de Carlos IV", dan rostro por un lado, a los aspectos comunes del vulgo de la época, y por otro, a la alta sociedad dominante. En este último cuadro interpretamos también Pintura por actividad profesional, pues lo realiza en función de su cargo oficial, y se da también en los dos restantes, pues no dejan de ser encargos por los que cobró, aunque coinciden también con la Pintura como testimonio histórico: ambos cuentan la tragedia de la guerra, la muerte a manos de los invasores, escenas violentas que precisamente ilustran la sangre que recorrió Madrid esos días de mayo. Los acontecimientos sociales y personales hacen que Goya acceda a temas que contrastan con sus trabajos anteriores, especialmente, con los de la Real Fábrica de Tapices. Las escenas y retratos desenfadados (como la "Familia de Carlos $I V$ ”) ahora se convertían en imágenes rebosantes de oscuridad, pues la Guerra y la enfermedad habían transformado el mundo de Goya, cuyas manifestaciones más sorprendentes vendrían en adelante.

\section{5- Goya: ocaso y exilio}

5.1) En medio del trasiego de la Guerra de Independencia, Goya realiza la serie de los "Desastres de la Guerra", ochenta estampas no publicadas y muchas de ellas sin fechar, que según Hughes (2004) tienen el posible detonante de una visita a Zaragoza poco después del inicio de la Guerra, siendo esta ciudad una gran opositora a Napoleón (p.310). 5.2) Pierde a Josefa Bayeu en 1812, y aunque en 1814 vuelve a estar al servicio de la Corona española, llegando a retratar a Fernando VII ("Fernando VII con manto real" (1814-1815)), en 1815 es desplazado de la Corte. 5.3) En 1819 adquiere la mansión conocida como "La Quinta del Sordo", a la que se mudará con Leocadia Zorrilla y sus dos hijos, según Sebastián (1979), para distanciarse de la Inquisición y de otra enfermedad a la que había sobrevivido gracias a su amigo Eugenio García Arrieta. Las paredes de la mansión albergaron las "Pinturas negras", que Prada (2010) entiende como el resultado psicológico de sus últimos padecimientos, mostrando un mundo interior sobre el cual, indica Hughes (2004), no tendría que rendir cuentas a nadie (p.421). Representan, para Todorov, un "desfile de demonios y de monstruos" (2011, p. 179), que podemos identificar, por ejemplo, en "El aquelarre o El gran Cabrón" (18201823), o en "La romería de San Isidro" (1823), donde, como en el resto de esa serie, afloran sus emociones, fantasmas y tormentos más profundos. ${ }^{\text {xxiv }}$

5.4) En 1823 Goya dona su mansión a su nieto, Mariano de Goya, y en 1824, con el permiso correspondiente, marcha a Francia, donde hay otros amigos exiliados. Se asienta en Burdeos, y de ahí viaja a París, donde pasa el verano en compañía de más amigos. En esta última etapa viaja a Madrid varias veces, por lo que, como afirma Todorov (2011), su exilio era flexible (p. 199), tanto como su apuesta por los nuevos formatos, como las estampas mediante la litografía, renovando la técnica de sus dibujos (p. 200) y manteniéndose productivo hasta su muerte en Burdeos en 1828, contando 82 años.

Goya en el hipertexto: multirrelato y motivaciones artísticas. Francisco García García y 
5.5. Relaciones: las más influyentes en Goya fueron:

5.5.1) Goya pierde a su esposa, Josefa Bayeu.

5.5.2) Trabajó para Fernando VII El deseado.

5.5.3) Sobrevive a otra enfermedad gracias a su amigo, el doctor Arrieta.

5.5.4) Vive con Leocadia Zorrilla sus últimos años.

5.5.5) Regala su mansión a su nieto, Mariano de Goya, en 1823.

5.6. Espacios: Goya se desenvolvió en:

5.6.1) Vive en Madrid el cambio de poder hacia Fernando VII.

5.6.2) Se muda a la "Quinta del Sordo" para cambiar de aires.

5.6.3) Se exilia en Burdeos, donde pasará sus últimos años, donde se asienta.

5.6.4) Visita París durante el verano de 1824.

5.7. Temáticas: Goya abordó: 5.7.1) Guerra; 5.7.2) Religión; 5.7.3) Folclore español; 5.7.4) Sociedad; 5.7.5) Clases bajas; 5.7.6) Clases altas; 5.7.7) Retratos. 5.8. Obras seleccionadas

5.8.1) "Desastres de la Guerra" "xxv (sin fecha exacta)

5.8.2) "Fernando VII con manto real". 1814-1815

5.8.3) "El aquelarre o El gran Cabrón". 1820-1823

5.8.4) "La romería de San Isidro". 1823

\subsection{Pintura por}

En esta última etapa de la vida de Goya observamos distintas motivaciones: los "Desastres de la Guerra" se asocian a la Pintura como testimonio histórico, ya que da forma a sucesos concretos de la guerra, con referencias obvias a la sociedad de la época. En el retrato de Fernando VII nos decantamos por la Pintura por actividad profesional dados los tiempos complicados de cambios de poder: Goya debía contentar al rey para alejarse de la lealtad jurada a José Bonaparte; pero también interpretamos Pintura como testimonio histórico, ya que ilustra la efigie de su monarca. Por último, se observa una Pintura por necesidad en las selecciones restantes. La cercanía de la muerte, tanto la ajena en la guerra, como la personal al volver a caer enfermo, el artista necesita desahogar las pulsiones interiores que le atormentan. La sombría "romería de San Isidro" contrasta claramente con obras previas como "La pradera de San Isidro"; ahora las personas son seres que se arrastran, moribundas, en un entorno oscuro, podrido. La sociedad está sumida en sus miserias, y éstas son las protagonistas para Goya. En " $E l$ aquelarre..." se observa cómo la monstruosa forma del macho cabrío marca la composición, también compuesta por seres decrépitos. Todos esos monstruos, esas incomodidades, sirven como desahogo personal de un Goya consciente de su propio fin.

\section{Análisis de resultados}

La propuesta desarrollada permite conformar una narración hipertextual haciendo uso de los apartados numerados de cada bloque del relato, de forma que es posible aunar dichos apartados según las preferencias y/o necesidades del usuario/lector. Hay un total de 103 enunciados, de entre los cuales 43 contienen enlaces a páginas web. Todos pueden combinarse para componer narraciones sobre Goya, dando un total de 10609 posibilidades (103x103), que a su vez son asociables a contenidos de otros autores, concretamente, en los cuatro primeros enunciados de cada bloque, pues el relato biográfico bebe de diversas fuentes bibliográficas.

Goya en el hipertexto: multirrelato y motivaciones artísticas. Francisco García García y 
La no linealidad viene marcada por las fronteras de los propios relatos (bloques/lexias), de manera que el usuario/lector puede utilizar esa información y otorgarle un orden distinto al biográfico que aquí se ha dado, e incluso componer otros mediante simplemente los enunciados derivados de los mismos. Así, en lugar de ser "1.1., 1.2, 1.3..." podría ser, por ejemplo, "1.1., 2.4, 1.5.2, 5.4, 3.7.5..." ofreciendo posibilidades textuales ricas y variadas. En la Figura 1 se ejemplifica la estructura hipertextual del bloque 1: en cada apartado hay una conexión con uno de los términos enlazados, que a su vez se remiten, en varios casos, a páginas web, pero que también están presentes en otros bloques.

Dichos enunciados se conectan, a su vez, con otros de los demás relatos en los que se repiten como ítems textuales. Si bien en cada bloque el apartado "temáticas" no ha sido enlazado de manera externa, es posible su relación en referencia al propio relato de Goya de esta construcción narrativa. En la imagen está el ejemplo del tema de la religión, presente a lo largo del corpus del relato. Hay, por tanto, referencias tanto del texto hacia afuera, como hacia adentro.

Por otro lado, también observamos la presencia de diferentes textos en cada bloque, pues las alusiones a autores también implican transtextualidad, al aunar diferentes textos en uno que a su vez es desglosable. En la Figura 1 ponemos como ejemplo la información biográfica de Goya procedente de la web del Museo del Prado (citada en la nota 16), de alguna manera presente en todos los bloques. 


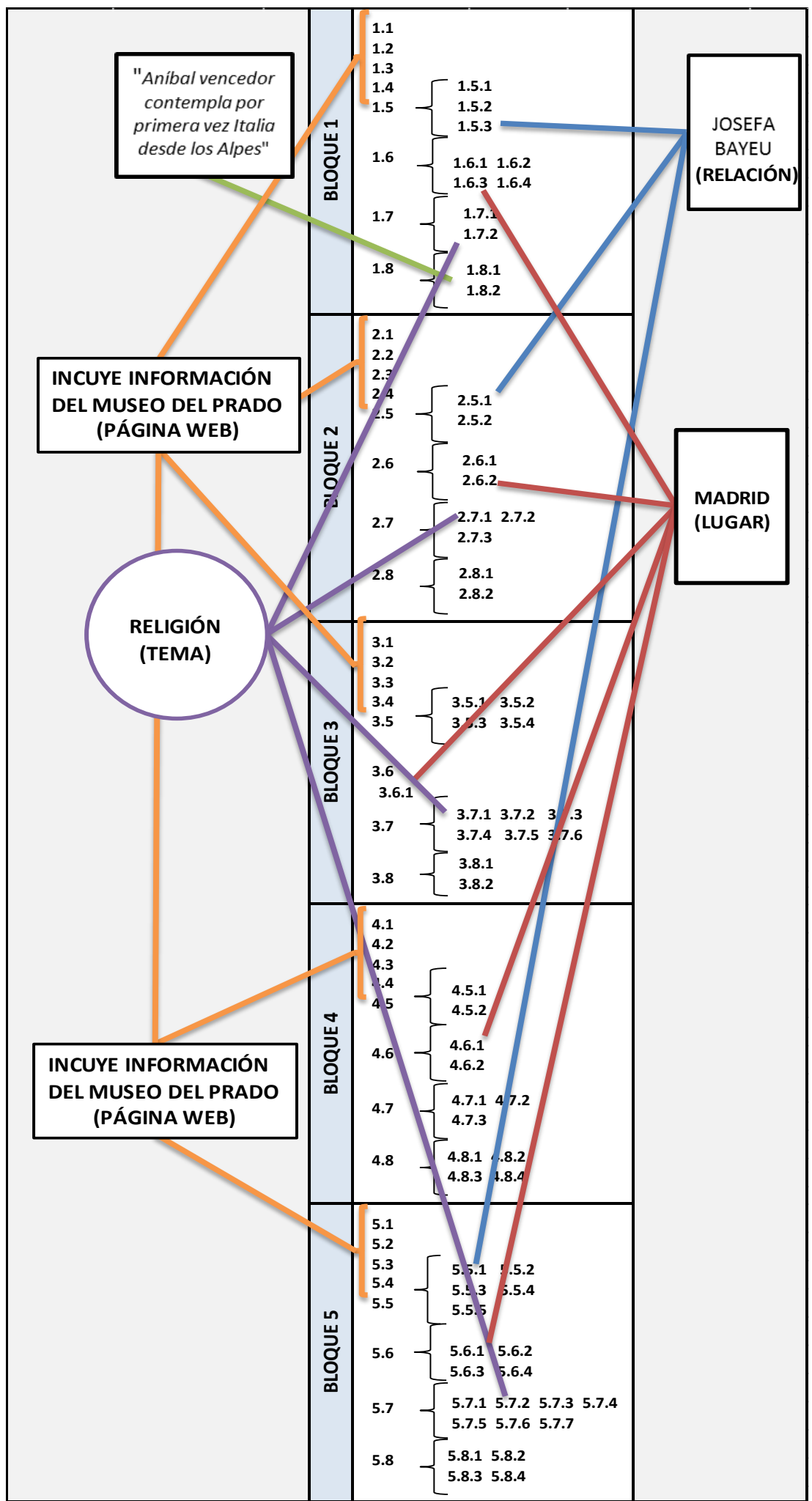

Figura 1: El hipertexto en Goya. Ejemplo de varias conexiones del primer bloque a través de varios epígrafes. Fuente: Elaboración propia.

Las obras seleccionadas han respondido favorablemente a la clasificación propuesta en referencia a la motivación del pintor, pues se prestan a una interpretación coherente de los enunciados. En la Figura 2 se observan los resultados de este apartado, de manera que la Pintura por actividad profesional está presente en todos los bloques; la Pintura 
por testimonio histórico, en los bloques 2, 4 y 5; la Pintura por placer, en el 3 y en el 4; y la Pintura por necesidad, en los bloques 3 y 5. Habiendo un total de 14 obras seleccionadas, la Pintura por actividad profesional está presente en 10 (71,42\%), la Pintura como testimonio histórico lo está en 7 (50\%), la Pintura por placer en 2 (14,28\%), y la Pintura por necesidad, en 3 (21,42\%).

\begin{tabular}{|c|c|c|c|c|c|}
\hline \multicolumn{2}{|c|}{$\begin{array}{l}\text { CLASIFICACIÓN DE LAS OBRAS SELECCIONADAS SEGÚN LAS } \\
\text { MOTIVACIONES DE GOYA }\end{array}$} & \multirow{2}{*}{$\begin{array}{l}\text { PINTURA POR } \\
\text { ACTIVIDAD } \\
\text { PROFESIONAL } \\
\mathbf{X} \\
\end{array}$} & \multirow{2}{*}{$\begin{array}{l}\text { PINTURA } \\
\text { COMO } \\
\text { TESTIMONIO } \\
\text { HISTÓRICO } \\
\end{array}$} & \multirow[t]{2}{*}{$\begin{array}{l}\text { PINTURA POR } \\
\text { PLACER }\end{array}$} & \multirow[t]{2}{*}{$\begin{array}{l}\text { PINTURA POR } \\
\text { NECESIDAD }\end{array}$} \\
\hline \multirow{2}{*}{ BLOQUE 1} & "Relicario de la Parroquia de Fuendetodos" & & & & \\
\hline & "Aníbal vencedor contempla por primera vez..." & $\mathbf{x}$ & & & \\
\hline \multirow{2}{*}{ BLOQUE 2} & "Adoración del nombre de Dios por los ángeles" & $\mathbf{x}$ & & & \\
\hline & "La pradera de San Isidro" & $\mathbf{x}$ & $\mathbf{x}$ & & \\
\hline \multirow{2}{*}{ BLOQUE 3} & "Cristo crucificado" & $\mathbf{x}$ & & & $\mathbf{x}$ \\
\hline & "Los duques de Osuna y sus hijos" & $\mathbf{x}$ & & $\mathbf{x}$ & \\
\hline \multirow{4}{*}{ BLOQUE 4} & "Caprichos" & & $\mathrm{x}$ & $\mathbf{x}$ & \\
\hline & "Familia de Carlos IV" & $\mathbf{x}$ & $x$ & & \\
\hline & El 2 de Mayo en Madrid o "La carga de los mamelucos" & $\mathbf{x}$ & $\mathbf{x}$ & & \\
\hline & El 3 de Mayo en Madrid o "Los fusilamientos" & $\mathbf{x}$ & $\mathbf{x}$ & & \\
\hline \multirow{4}{*}{ BLOQUE 5} & "Desastres de la Guerra" & & $\mathbf{x}$ & & \\
\hline & "Fernando VII con manto real" & $\mathbf{x}$ & $\mathbf{x}$ & & \\
\hline & "El aquelarre" o "El gran cabrón" & & & & $\mathbf{x}$ \\
\hline & "La romería de San Isidro" & & & & $\mathbf{x}$ \\
\hline
\end{tabular}

Figura 2: Tabla con la clasificación de las obras seleccionadas según motivaciones de Goya. Fuente: elaboración propia.

El número de obras en las que aparecen dos tipos de motivación son ocho, que se corresponde con un $57,14 \%$, detectándose solo una en las seis restantes $(42,85 \%)$. La Pintura por actividad profesional coincide con la Pintura por necesidad en una ocasión, en otra, con la Pintura por placer, y en cinco ocasiones, con la Pintura como testimonio histórico, que también coincide en otro caso con Pintura por placer. Predomina, en definitiva, la Pintura por actividad profesional, que además es la que más combinaciones presenta con otras motivaciones. Se subraya así el compromiso eminentemente profesional de Goya en la muestra.

\section{Discusión}

Construir el multirrelato de Goya ha entrañado grandes retos. Obedeciendo a la pragmática del trabajo, de carácter experimental, y a las necesidades formales de extensión del mismo, se omitieron hechos y obras que el lector echará en falta. No obstante, tanto el relato como la muestra de obras seleccionadas han resultado adecuadas para confirmar las hipótesis y alcanzar los objetivos propuestos (ver conclusiones).

Para los enlaces a páginas web se ha procurado elegir páginas institucionales, si bien el usuario/lector podrá pensar en otras posibilidades, a su juicio, más adecuadas para consolidar una narración sobre Goya.

En último lugar, sería de interés continuar esta línea de investigación profundizando en las motivaciones de Goya, en los estudios de recepción de la obra de Goya a través de 
tipo de construcción online, en la participación ciudadana en la gestación de nuevos relatos, en la implicación del lectoautor en este tipo de construcción, y también en el estudio de la convergencia lectora y participativa entre la lectura presencial y la lectura digital online.

\section{Conclusiones}

Las hipótesis formuladas en este trabajo, junto con los objetivos, se confirman y alcanzan respectivamente con la construcción hipertextual realizada: por un lado, es posible "desglosar" a Goya según los principios narrativos del hipertexto, dando lugar a una serie de posibilidades textuales, un multirrelato, que bien puede servir al ciudadano para distintos intereses dadas las opciones de que así dispone para conocer a Goya y a su obra. Por otro, queda comprobada la viabilidad de clasificar la obra de Francisco de Goya y Lucientes en los cuatro tipos de motivación propuestos, cuatro formas de comprender sus pinturas a través de tintes biográficos.

El hipertexto, aplicado a una materia de estudio, supone una herramienta narrativa para el enriquecimiento cultural del ciudadano: le posibilita nutrirse mediante relatos que él mismo completa con su interactividad y navegación. La simultaneidad de contenidos interconectados agudiza su participación en la materia, y esa implicación desemboca en interactividad, consulta de fuentes, lectura de ideas, consideración de postulados y aprendizaje. El hipertexto invita al interés, a la curiosidad; la navegación no lineal es un principio de orden, pues aunque un usuario/lector se introduzca en el relato de forma no lineal mediante lexias, puede componer una idea general o abstracta del mismo. Este relato hipertextual aquí construido reproduce cómo se puede acceder a un gran relato o multirrelato, en este caso creado a partir de fuentes y referencias bibliográficas, desglosado en ítems concretos conectables a otros ítems y textos. Supone un ejemplo claro y necesario de cómo el ciudadano puede acceder a la cultura en la actualidad, en este caso, a Goya.

En referencia al modelo de clasificación por motivación, es accesible para profundizar en la obra, naturaleza y vivencias de Goya. Se observa en la muestra un predominio de Pintura por actividad profesional (71,42\%), que comparte con otras conforme pasa el tiempo y que desemboca, en las últimas dos obras, en una necesidad psicológica, subjetiva, personal. Todos actuamos movidos por algo, y el análisis de la historia y del arte desde esta perspectiva resulta coherente y oportuno.

Cabe destacar que, además de estas aportaciones, hay que incidir también en el valor de esta investigación que propone la transferencia de este tipo de construcción hipertextual a otras situaciones y ámbitos, soportes, medios, géneros y formatos.

Goya sigue vigente en nuestro siglo; se ha codificado en datos, como el resto de la realidad, y a pesar de los factores negativos que pueda albergar el mundo cibernético, es imposible despreciar las posibilidades culturales y narrativas que lo digital ofrece a nuestro desarrollo social y cultural, pues en términos educativos, como bien señala Vera Silva (2017), el estudiante digital autónomo, puede abordar la realidad y los problemas que presenta conectando épocas, reflexionando, e interactuando en cualquier escala. En términos de Débrais (2001) diremos que lo digital no solo comunica, también transmite conocimientos, y mediante el multirrelato podemos alcanzar ambas metas. 
En el Anexo del trabajo se encuentran las referencias de los enlaces del experimento.

\section{Agradecimientos}

Los autores agradecen a Raquel Acinas Martín el tiempo compartido recorriendo la obra de Goya en el Museo Nacional del Prado. Una visita didáctica, emocionante, y en suma, inolvidable.

Presentación del Artículo: 19 de junio de 2018

Fecha de aprobación: 24 de septiembre de 2018

Fecha de publicación: 30 de octubre de 2018

García García, F.; Gil Ruiz, F.J. (2018). Goya en el hipertexto: Multirrelato y motivaciones artísticas. RED. Revista de Educación a Distancia, 58. Consultado el (dd/mm/aaaa) en http://www.um.es/ead/red/58

\section{Financiación}

Artículo incluido en el Proyecto ENECORES (Estrategias Narrativas del Empoderamiento Ciudadano a través del Open Data y las Redes Sociales), cofinanciado en un 91,87\% por el Fondo Social Europeo dentro del Programa Operativo de Empleo Juvenil 2014-2020), y de la Iniciativa de Empleo Juvenil (YEI). Referencia PEJD2016/SOC-3063.

\section{8- Referencias}

Aarseth, E.J. (1997). "No linealidad y teoría literaria", en Landow, G.P., Teoría del hipertexto. Barcelona: Paidós, pp. 71-108.

Alcalá Flecha, R. (1993). "El vampirismo en la obra de Goya". Goya. Revista de Arte, 233, pp. 258-267.

Alcalá Flecha, R. (1997). "Goya y el mito de las parcas". Goya. Revista de Arte, 258, pp. 337-351.

Alcalá Flecha, R. (2000). "Saturnismo y brujería en dos caprichos de Goya". Goya. Revista de Arte, 274, pp. 3-9.

Antigüedad del Castillo-Olivares, M. D. (2009-2010). "Goya, las mujeres y la Guerra de Independencia". Espacio, Tiempo y Forma, Serie VII, $H^{a}$ del Arte, 22-23, pp. 157-182.

Arias-Robles, F. y García-Avilés, J.A. (2016): Definiendo la hipertextualidad. Análisis cuantitativo y cualitativo de la evolución del concepto, Icono 14, volumen 14 (2), pp. 48-68. doi: 10.7195/ri14.v24i2.995

Aristóteles. (2013). Poética. Madrid: Alianza Editorial.

Barthes, R. (2004). S/Z. Buenos Aires: Siglo XXI. 
Benjamin, W. (2015). La obra de arte en la era de su reproductibilidad técnica. Buenos Aires: Gedisa.

Bush, V. (1945). “As we may think”. Atlantic Monthly, 176, pp. 101-108.

Campás, J. (2007). El hipertexto. Los blogs. Barcelona: Editorial UOC.

Castells, M. (2010). Comunicación y poder. Madrid: Alianza Editorial.

Chatman, S. (2013). Historia y discurso. La estructura narrativa en la novela y en el cine. Barcelona: RBA.

Claes, F.; Deltell, L. (2014). "Museos sociales. Perfiles museísticos en Twitter y Facebook 2012-2013”. El profesional de la información, v. 23, n. 6, noviembrediciembre, pp. 594-602. http://dx.doi.org/10.3145/epi.2014.nov.06

Codina, L. (1998). "H de Hypertext, o la teoría de los hipertextos revisitada.". Cuadernos de documentación multimedia, $\mathrm{n}^{\mathrm{o}}$ 6-7. Recuperado de https://pendientedemigracion.ucm.es/info/ multidoc/multidoc/revista/cuad67/codina.htm

Contursi, M.E.; Ferro, F. (2000). La narración. Usos y teorías. Buenos Aires: Grupo Editorial Norma.

Cordón, J.A. (2016). "La lectura en el entorno digital: nuevas materialidades y prácticas discursivas". Revista chilena de literatura, 94, pp. 15-8

De Pablos, J. (2004). "De Velázquez al Hipertexto: algunas implicaciones socioculturales". Aula Abierta, 84, pp. 103-116.

Debrais, R. (2001). Introducción a la mediología. Barcelona: Paidós.

Fernández, E. P. (2017). Big data: eje estratégico en la industria audiovisual. Barcelona, ESPAÑA: Editorial UOC. Retrieved from http://www.ebrary.com

Freeland, C. (2003). Pero ¿esto es arte? Una introducción a la teoría del arte. Madrid: Cátedra.

García, F.; Gértrudix, M. (2009). "El Mare Nostrum Digital: mito, ideología y realidad de un imaginario socio-técnico". Revista Icono14 [en línea] 1 de junio de 2009, $N^{o}$ 12. pp. 07-30. Recuperado (18/07/2017) de http://www.icono14.net

García García, F. (2006). "Contenidos educativos digitales: Construyendo la Sociedad del Conocimiento". Red digital. Revista de Tecnologías de la información y la comunicación educativas, 6, pp. 1-29.

García García, F. (2002). "La narrativa hipermedia aplicada a la educación”. Revista Red Digital, (3) (sin paginar) 
Genette, G. (1979). Palimpsestos. La literatura en segundo grado. Madrid: Taurus.

Gértrudix-Barrio, F.; Gálvez de la Cuesta, M.C.; Said-Hung, E.; Durán-Medina Correo, J.F. (2016). "Alfabetización digital, competencias mediáticas y Open Data". RELATEC: Revista Latinoamericana de Tecnología Educativa, Vol 15(2), pp. 113-121. DOI: 10.17398/1695288X.15.2.113

Giraldo-Dávila, A. F. y Maya-Franco, C. M. (2016). Modelos de ecología de la comunicación: análisis del ecosistema comunicativo. Palabra Clave, 19(3), 746768. DOI: $10.5294 /$ pacla.2016.19.3.4

Gros, B. (2012). Retos y tendencias sobre el futuro de la investigación acerca del aprendizaje con tecnologías digitales. Revista de Educación a Distancia, (32), pp. 1-13.

Guijarro Castro, C. (2013). "La influencia de la enfermedad neurológica de Goya en su cambio de estilo pictórico". Neurosciences and History, 1 (1), pp. 12-20.

Han, B. (2013). La sociedad de la transparencia. Barcelona, ES: Herder Editorial. Retrieved from http://www.ebrary.com

Han, B. (2014). En el enjambre. Barcelona, ES: Herder Editorial. Retrieved from http://www.ebrary.com

Hofmann, W. (1995). Une époque en rupture, 1750-1830. París, Gallimard.

Hugues, R. (2004). Goya. Barcelona: Círculo de lectores.

Jacobs, H.C. (2016-2017). "Nacionalismos en la pintura de Francisco de Goya", Acta/Artis. Estudis d'Art Modern, 4-5, pp. 55-75.

Jenkins, H. (2003)." Transmedia Storytelling. Moving characters from books to films to video games can make them stronger and more compelling". Technology

Review, recuperado de https://www.technologyreview.com/s/401760/transmedia-storytelling/

Jenkins, H. (2008). Convergence culture: la cultura de la convergencia de los medios de comunicación. Barcelona: Paidós.

Kerlov, I. V., y Rosenbush, J. (1986). Computer Graphics for Designers and Artists. Nueva York, Van Nostrand Reinhold.

Landow, G.P. (1992). Hipertexto: la convergencia de la teoría crítica contemporánea y la tecnología. Barcelona: Paidós.

Landow, G.P. (1997). "Qué puede hacer el crítico? La teoría crítica en la edad del hipertexto”, en Landow, G.P., Teoría del hipertexto. Barcelona: Paidós, pp. 1770. 
Lévi, P. (1999). ¿Qué es lo virtual? Barcelona: Paidós.

Liestol, G. (1997). "Wittgenstein, Genette y la narrativa del lector", en Landow, G.P., Teoría del hipertexto. Barcelona: Paidós, pp. 109-146.

López Valero, A., Jerez Martínez, I. (2015). “Textualidad digital y multialfabetización. Los contenidos digitales como material educativo”. Educatio Siglo XXI, Vol. 33 $\mathrm{n}^{\mathrm{o}} 2 \cdot 2015$, pp. 165-182. http://dx.doi.org/10.6018/j/233191

Manovich, L. (2005). El lenguaje de los nuevos medios de comunicación. La imagen en la era digital. Barcelona: Paidós.

Martín Bravo, A. M. (2015). "La información, un recurso en alza: El futuro de la documentación en los museos". Complutum, 2015, Vol. 26 (2), pp. 157-163. http://dx.doi.org/10.5209/rev_CMPL .2015.v26.n2.50426

Mena, M.; Gudrun. (2008). «El encargo del Dos y el Tres de mayo en Madrid» en Goya en tiempos de Guerra. Catálogo, Madrid, Museo del Prado, pp. 353 y ss.

Mihura López, R.; Barneche Naya, V.; Hernández Ibáñez, L. A. (2012): “Los sistemas multimedia digitales interactivos en los museos". Vivat Academia. $\mathrm{n}^{\circ} 117 \mathrm{E}$, pp. 1298-1306. http://www.ucm.es/info/vivataca/numeros/n117E/DATOSS.htm

Monino, J., \& Sedkaoui, S. (2016). Big data, open data and data development. Hoboken, New Jersey: ISTE Ltd/John Wiley and Sons Inc. Recuperado de http://proquest.safaribooksonline.com/book/ databases/businessintelligence/9781848218802

Moreno, I. (2012). Narrativa Hipermedia y Transmedia, en Victoria Perales Blanco (Ed.) (Coord.), Creatividad y discursos hipermedia. Murcia: Ediciones Universidad de Murcia, pp. 21-40.

Murray, J. H. (1999). Hamlet en la holocubierta. El futuro de la narrativa en el ciberespacio. Barcelona: Paidós.

Museo del Prado. (s.f.). Goya y Lucientes, Francisco de. Web Museo del Prado. Recuperado de https://www.museodelprado.es/coleccion/artista/goya-ylucientes-francisco-de/39568a17-81b5-4d6f-84fa-12db60780812

Nelson, T.H. (1965). "Complex Information Processing. A File Structure for The Complex, The Changing and the Indeterminate" en ACM 20th National Conference, pp. 84-100.

Ortega Santamaría, S. (2004). Multimedia, hipermedia y aprendizaje. Construcción de espacios interactivos. Salamanca: Publicaciones Universidad Pontificia de Salamanca.

Ortega y Gasset, J. (1980). Papeles sobre Velázquez y Goya. Madrid: Alianza editorial.

Goya en el hipertexto: multirrelato y motivaciones artísticas. Francisco García García y 
Ortega y Gasset, J. (2016). La deshumanización del arte y otros ensayos de estética. Barcelona: Austral.

Parra, S. (11 de 05 de 2015). Papelenblanco. Obtenido de papelenblanco: http://www.papelenblanco.com/divulgacion/consilence-la-unidad-delconocimiento-de-edward-o-wilson.

Prada, J. de (2008). Goya y las pinturas negras desde la psicología de Jung. Madrid: Editores Asociados.

Prada, J. de (2010). "La dimensión inconsciente en la obra de carácter fantástico de Goya y su repercusión en la atribución del Coloso". Goya. Revista de Arte, $\mathrm{n}^{\circ}$ 331, pp. 320-339.

Prósperi, G. O. (2016). El texto como palimpsesto. Reflexiones en torno a la lectura literaria. Revista Chilena De Literatura, (93), 215-234. Retrieved from http://0search.proquest. com.cisne.sim.ucm.es/docview/1847779147?accountid=14514

Quéau, P. (1995). Lo virtual. Virtudes y vértigos. Barcelona: Paidós.

Sebastián, S. (1979). Interpretación iconológica de las «pinturas negras» de Goya. Goya. Revista de Arte, 148-150, pp. 268-277.

Scolari, C.A. (2013). Narrativas transmedia. Cuando todos los medios cuentan. Barcelona: Planeta.

Todorov, S. (2011). Goya. A la sombra de las luces. Barcelona: Círculo de lectores.

Torres, P. C. R. (2009). Hipermedia como narrativa Web posibilidades desde la periferia. Bogotá, CO: Red Signo y Pensamiento. Retrieved from http://www.ebrary.com

Urrea, J. (1993). “Goya en Italia. A propósito del Aníbal”. Boletín del Museo Nacional del Prado, tomo 14 (32), pp. 59-66.

Vera Silva, A.A. (2017). La autonomía del estudiante digital en la sociedad del conocimiento. Bucaramanga: La Bastilla Soluciones Integrales SAS.

Villar, M. A. (2001). "Goya en el relato cinematográfico". Cuadernos de Historia Contemporánea, 23, pp. 67-102.

Wilson, O.E. (1999). Consilience. La unidad del conocimiento. En O.E. Wilson, Consiliense. La unidad del conocimiento. (p. 484). Barcelona: Círculo de lectores.

Woods, L. (1998). "Volverse heterarca: sobre la teoría tecnocultural, la ciencia menor, y la producción de espacio" en ARONOWITZ, S., MARTINSONS, B. y MENSER, M. (1998). "Tecnociencia y cibercultura. La interrelación entre cultura, tecnología y ciencia”. Barcelona: Paidós Multimedia. 


\section{9- Anexo: Referencias de los enlaces del experimento}

A continuación se muestran las referencias referentes al ejercicio realizado. Para evitar repeticiones innecesarias, aquellos enlaces repetidos en varios bloques solo se han citado una vez (en el primer bloque en que aparecen)

\subsection{Primer bloque}

Contacto (s.f). Fundación Fuendetodos Goya. Recuperado de https://fundacionfuendetodosgoya.org/contacto/ Consultado el 15/10/2017

Goya y Lucientes, F. de (s.f). Aníbal vencedor, que por primera vez miró Italia desde los Alpes. Fundación Goya en Aragón. Recuperado de http://www.fundaciongoyaenaragon.es/goya/obra/catalogo/?ficha=153\&titulo=a n\%C3\%ADbal\&imagenporpagina $=1 \&$ from $=/$ goya/obra/catalogo/pagina/1/\&titul $\mathrm{o}=\mathrm{an} \% \mathrm{C} 3 \%$ ADbal\&imagenporpagina $=1$. Consultado el 20/12/2017

Goya y Lucientes, F. de (s.f). Relicario de la Parroquia de Fuendetodos. Fundación Goya en Aragón. Recuperado de http://www.fundaciongoyaenaragon.es/goya/obra/catalogo/?ficha=91

Consultado el 26/10/2017 (también en segundo bloque)

Goya, F. (s.f). Josefa Bayeu. Gallery G., Allart.biz. Recuperado de http://allart.biz/photos/image/Bayeu_2.html Consultado el 26/10/2017 (También en segundo y quinto bloques)

Gran enciclopedia aragonesa. (s.f). José Luzán. Recuperado de http://www.enciclopedia-aragonesa.com/voz.asp?voz_id=8299 Consultado el $26 / 10 / 2017$

Madrid. (s/f). Inicio. Ayuntamiento de Madrid. Recuperado de http://www.madrid.es/portal/site/munimadrid. Consultado el 29/10/2017 (presente en segundo, tercero, cuarto y quinto bloques)

Museo del Prado. (s.f). Francisco Bayeu y Subías. https://www.museodelprado.es/aprende/enciclopedia/voz/bayeu-y-subiasfrancisco/2a747128-35c6-492d-b611-6d2461227323 Consultado el 26/10/2017 (presente en segundo y tercer bloques)

Museo del Prado. (s/f). Francisco de Goya y Lucientes. Recuperado de https://www.museodelprado.es/coleccion/artista/goya-y-lucientes-franciscode/39568a17-81b5-4d6f-84fa-12db60780812 Consultado el 20/09/2017

Roma. (s/f). Roma Capitale. Siti istituzionale. Recuperado de http://www.comune.roma.it/pcr/do/jpsite/Site/home Consultado el 20/09/2017

Goya en el hipertexto: multirrelato y motivaciones artísticas. Francisco García García y 
Zaragoza. (s/f). La web de la ciudad de Zaragoza. Ayuntamiento de Zaragoza. Recuperado de http://www.zaragoza.es/sedeelectronica/ Consultado el 20/09/2017 (también en segundo bloque)

\subsection{Segundo bloque}

Goya y Lucientes, F. de "La pradera de San Isidro", en Museo Nacional del Prado. https://www.museodelprado.es/coleccion/obra-de-arte/la-pradera-de-sanisidro/290d61bb-59ac-49e5-a63f-390eb5bdde46 Consultado el 26/10/2017.

Goya y Lucientes, F. de(s/f). "Adoración del nombre de Dios por los ángeles", Fundación Goya en Aragón, http://www.fundaciongoyaenaragon.es/goya/obra/catalogo/?ficha=613

Consultado el 26/10/2017

UNED Documentos. (2013). La Real Fábrica de Tapices. https://www.youtube.com /watch?v= UsPigJacvDQ Consultado el 25/09/2017 (Ítem también presente en el tercer bloque, con otro enlace)

\subsection{Tercer bloque}

Academia de las Artes de San Fernando. (s/f). Página principal. Recuperado de http://www.realacademiabellasartessanfernando.com/es Consultado 26/09/2017

Glendinning, N. (s/f). "Colección de los duques de Osuna". Museo Nacional del Prado. Recuperado de https://www.museodelprado.es/aprende/enciclopedia/voz/coleccion-de-losduques-de-osuna/22685fad-799c-43b8-8439-eacc83e026a7 Consultado el $25 / 09 / 2017$

Goya y Lucientes, F. de (s/f). "Carlos III, cazador". Museo del Prado. Recuperado de https://www.museodelprado.es/coleccion/obra-de-arte/carlos-iii-

cazador/32f3cf01-f8d2-4be1-b12a-aa04668706d7 Consultado el 26/10/2017 (también en cuarta etapa)

Goya y Lucientes, F. de (s/f). "Cristo crucificado". Museo Nacional del Prado. Recuperado de https://www.museodelprado.es/coleccion/obra-de-arte/cristocrucificado/093cbda0-b9c4-445e-b6d3-56c423811f46 Consultado el 26/09/2017

Goya y Lucientes, F. de (s/f). "Los duques de Osuna y sus hijos". Museo Nacional del Prado. Recuperado de https://www.museodelprado.es/coleccion/obra-dearte/los-duques-de-osuna-y-sus-hijos/09085b96-441d-40e3-9092-9230bbe1fa99 Consultado el 26/09/2017

Real Fábrica de Tapices. (s/f). http://realfabricadetapices.com/ Consultado 26/09/2017

Región de Murcia.com (s/f). Conde de Floridablanca. Recuperado de http://www.regmurcia.com/servlet/s.Sl?sit=c,373,m,1207\&r=ReP-1841-

DETALLE_REPORTAJESPADRE Consultado el 25/09/2017

Goya en el hipertexto: multirrelato y motivaciones artísticas. Francisco García García y 


\subsection{Cuarto bloque}

Enciso Recio, L.M. (s/f). "Colección de Carlos IV". Museo del Prado. Recuperado de https://www.museodelprado.es/aprende/enciclopedia/voz/coleccion-de-carlosiv/f1094cbd-7bfb-4b99-97fa-04769b0a3954 Consultado el 29/10/2017

Goya y Lucientes, F. de (s/f). "La familia de Carlos IV". Museo Nacional del Prado. Recuperado de https://www.museodelprado.es/coleccion/obra-de-arte/la-familiade-carlos-iv/f47898fc-aa1c-48f6-a779-71759e417e74 Consultado el 27/09/2017

Goya y Lucientes, F. de (s/f). El 2 de Mayo de 1808 en Madrid o "la lucha con los mamelucos". Museo del Prado. Recuperado de https://www.museodelprado.es/coleccion/obra-de-arte/el-2-de-mayo-de-1808en-madrid-o-la-lucha-con-los/57dacf2e-5d10-4ded-85aa9ff6f741f6b1?searchMeta=2\%20de\%20mayo Consultado el 26/10/2017

Goya y Lucientes, F. de (s/f). El 3 de Mayo en Madrid o "Los fusilamientos". Museo del Prado. Recuperado de https://www.museodelprado.es/coleccion/obra-dearte/el-3-de-mayo-en-madrid-o-los-fusilamientos/ 5e177409-2993-4240-97fb847a02c6496c Consultado el 27/09/2017

Jordán de Urríes y de la Colina, J. (s/f). "María Luisa de Parma, princesa de Asturias [Mengs]". Museo del Prado. Recuperado de https://www.museodelprado.es/aprende/enciclopedia/voz/maria-luisa-de-parmaprincesa-de-asturias-mengs/b0ac9a99-26a4-426f-8049-3944a8a920fc Consultado el 26/10/2017.

Lucio, C.G. (28/04/2017). ¿Por qué se quedó sordo Goya? Diario El Mundo, http://www.elmundo.es/ciencia-ysalud/salud/2017/04/28/59031fb3ca474167398b464f.html Consultado el $27 / 09 / 2017$

Museo Nacional del Prado (s/f). "Explora la colección. Copias de los caprichos de Goya". Recuperado de https://www.museodelprado.es/coleccion/obras-dearte? search=copias $\% 20 \mathrm{de} \% 201$ os $\% 20$ caprichos $\% 20 \mathrm{de} \% 20$ goya\&ordenarPor $=\mathrm{p}$ m:relevance Consultado el 26/10/2017.

Sevilla. (s/f). Ayutamiento de Sevilla. http://www.sevilla.org/ Consultado el 28/09/2017

\subsection{Quinto bloque}

Aterido, Á. (s/f). "Colección de Fernando VII", en Museo Nacional del Prado. Recuperado de https://www.museodelprado.es/aprende/enciclopedia/voz/coleccion-defernando-vii/1fd09a07-e3e0-4bca-945f-1506b871fc2b Consultado el 26/10/2017 
Bordeaux. (s/f). Site officiel de la ville de Bordeaux, http://www.bordeaux.fr/ Consultado el 01/10/2017

Fraguas, R. (01/12/2015). Visita la Quinta del Sordo. Periódico El País, https://elpais.com/ccaa/2015/11/30/madrid/1448906853_374509.html Consultado el 01/10/2017

Goya y Lucientes, F. de. (s/f). "El aquelarre o El gran cabrón”, en Museo Nacional del Prado. Recuperado de https://www.museodelprado.es/coleccion/obra-dearte/el-aquelarre-o-el-gran-cabron/09559184-cfeb-48fe-8acc-89b070b64d92 Consultado el 01/10/2017

Goya y Lucientes, F. de. (s/f). "Portrait of Mariano Goya, the Artist's Grandson" en Meadows Museum, Dallas. Recuperado de https://meadowsmuseumdallas.org/collections/pages/Obj2238/?sid $=28 \& \mathrm{x}=94884$ Consultado el $01 / 10 / 2017$

Goya y Lucientes, F. de. (s/f). "Self-Portrait with Dr. Arrieta", en Minneapolis Institute for Art. Recuperado de https://collections.artsmia.org/art/1226/self-portrait-withdr-arrieta-francisco-jose-de-goya-y-lucientes Consultado el 01/10/2017

Goya y Lucientes, F. de. (s/f). "Una manola: Leocadia Zorrilla", en Museo Nacional del Prado. Recuperado de https://www.museodelprado.es/coleccion/obra-dearte/una-manola-leocadia-zorrilla/8dab47d2-3f3c-4612-81f7-5808268e8a76 Consultado el 26/10/2017

Goya y Lucientes, F. de. (s/f)." Fernando VII con manto real", en Museo Nacional del Prado. Recuperado de https://www.museodelprado.es/coleccion/obra-dearte/fernando-vii-con-manto-real/1b46165d-1ef7-4399-8282-7056bb901ad9 Consultado el 26/10/2017.

Goya y Lucientes, F. de. (s/f)." La romería de San Isidro", en Museo Nacional del Prado. Recuperado de https ://www.museodelprado.es/coleccion/obra-de-arte/laromeria-de-san-isidro/d6d92063-15a9-4cfb-a7be-3576a2f8b87e Consultado el $01 / 10 / 2017$

Goya y Lucientes, Francisco de. (s/f). "Desastres de la Guerra”, en Museo Nacional del Prado. https://www.goyaenelprado.es/obras/lista/?tx_gbgonline_pi1\%5Bgocollectionids $\% 5 \mathrm{D}=27$ Consultado el 20/12/2017

Paris (s/f) Site officiel de la ville de Paris. https://www.paris.fr/ Consultado el $01 / 10 / 2017$

\footnotetext{
${ }^{\mathrm{i}}$ Manovich (2005) explica la continuidad citando a Kerlov, Isaac Victor, y Rosenbush, Judson (1986).

${ }^{\text {ii }}$ Contursi y Ferro (2000) realizan un recorrido a lo largo de las teorías narrativas más importantes.

iii Aarseth (1997, p. 84)
} 
${ }^{\text {iv }}$ Aarseth puntualiza que el término Hipertexto fue introducido por Nelson (1965), si bien la idea original se debe al artículo "As we may think" (Bush, 1945)

${ }^{v}$ Documento no paginado.

${ }^{v i}$ Arias-Robles y García-Avilés abordan en su estudio la historia del concepto de hipertexto, partiendo de 1965.

${ }^{v i i}$ Citado por Scolari (2013)

viii La definen, citando a Costa (2011), como una clasificación estadística de las actividades comunicativas humanas en un territorio (p. 752).

${ }^{\text {ix }}$ El autor cita en este apartado a Woods (1998, p. 328).

${ }^{x}$ El autor se refiere a Wilson (1999) y a Parra (2015) para tratar este tema.

${ }^{x i}$ Roberto Alcalá Flecha aborda en varios trabajos la plasmación de mitos y creencias populares en la obra de Goya. Caben destacar "Goya y el mito de las parcas" (1997), y "Saturnismo y brujería en dos caprichos de Goya" (2000). También señala a Goya en otro estudio (1993) como un precursor del vampirismo, al relacionar la figura del vampiro con los políticos y religiosos de la época (el vampiro político-religioso) en sus caprichos "Desastres de la Guerra".

xii Todorov (2011) realiza esta distinción en la obra de Goya (p. 211).

xiii Ortega y Gasset (1980) ya se acercó superficialmente a las mismas. Este estudio pretende ir más allá en la deducción de una coherencia interna entre la vida y la obra de Goya aprovechando el hipertexto.

xiv A este respecto, conviene atender a Lévi (1998), especialmente al capítulo "La virtualización del texto".

${ }^{\mathrm{xv}}$ Citado previamente en su definición de Hipertexto.

${ }^{x v i}$ Resulta inviable abarcar cada punto y cada coma de la vida y obra de este personaje histórico, pero a pesar de ello, el estudio ofrece el acercamiento, conocimiento y comprensión de la vida y obra del pintor.

xvii Además de los autores citados a lo largo de este apartado, el relato biográfico se ha elaborado consultando también la biografía de Goya en la web del Museo del Prado: https://www.museodelprado.es /coleccion/artista/goya-ylucientes-francisco-de/39568a17-81b5-4d6f-84fa-12db60780812

xviii Jesús Urrea (1993) confirmó la autoría de Goya sobre el cuadro al compararlo con los bocetos que se tenían, así como con las condiciones de participación en el concurso de Parma.

${ }^{\text {xix }}$ Hughes (2004) subraya las estrechas relaciones entre Goya y esta familia, destacando el retrato de grupo "Familia de Osuna" (1788).

${ }^{x x}$ Recientemente este tema pudo leerse en la prensa: http://www.elmundo.es/ciencia-y-salud/salud/2017/04/28 /59031fb3ca4 74167398b464f.html

xxi A este respecto Hughes (2004) explica la naturaleza de los "Caprichos". (pp. 205- 246)

xxii Antigüedad del Castillo-Olivares (2009-2010, p. 179) cita, a propósito de la gestación de los cuadros, a Manuela Mena y Gudrun Maurer, «El encargo del Dos y el Tres de mayo en Madrid».

xxiii No se trata de un cuadro individual, ni de cuadros siquiera, pero dada la riqueza formal de Goya, en este caso tendremos en cuenta la premisa "pintura por" como aplicable a su actividad artística. Decidimos incluir los "Caprichos" por las implicaciones personales y sociales que éstos tienen en Goya.

xxiv Todorov (2011) cita a Werner Hofmann (1995) al abordar la idea de que con las pinturas negras Goya se exorcizaba a sí mismo. (p. 181)

${ }^{\mathrm{xxv}}$ Esta serie tiene el mismo tratamiento que el que aplicamos previamente a los "Caprichos". 